\title{
Divisas ocasionales o invenciones españolas en un cancionero manuscrito del duque Charles III de Crö̈

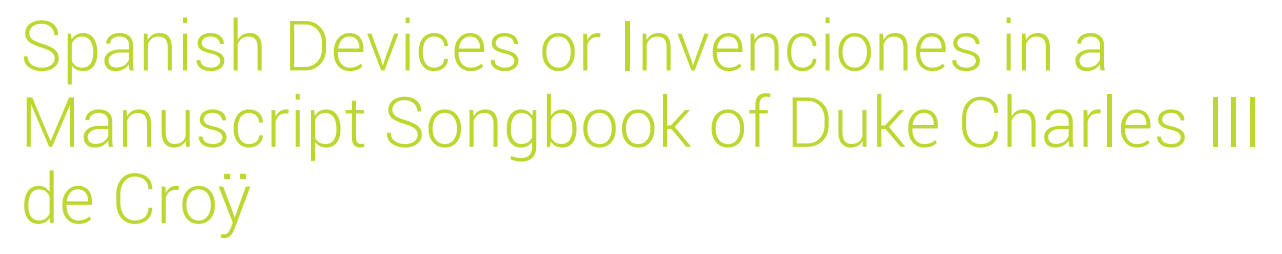

\section{Sagrario López Poza}

http://orcid.org/0000-0003-1852-7938

Universidade da Coruña

ESPAÑA

sagrario.lopez.poza@udc.es

[Hipogrifo, (issn: 2328-1308), 8.1, 2020, pp. 453-469]

Recibido: 09-04-2020 / Aceptado: 29-05-2020

DOI: http://dx.doi.org/10.13035/H.2020.08.01.31

Resumen. Entre las creaciones más ingeniosas y sutiles de la cultura cortesana bajomedieval y renacentista están las divisas o empresas, artefactos híbridos que mediante la palabra y la imagen enviaban un mensaje de su propietario a quienquiera que las mirara. De la modalidad de carácter ocasional (y a menudo efímera) conocida en España como "invenciones", que se ostentaba en acontecimientos festivos (torneos, juegos de cañas, etc.) raras veces se conservan testimonios con la imagen. Por ello resulta excepcional el hallazgo en una biblioteca francesa de un manuscrito que reproduce veinte invenciones españolas (difundidas en el Cancionero general y otras fuentes) de las que ofrece no solo el mote, sino también la pictura o dibujo. Este trabajo informa sobre el creador del manuscrito y detalla cuáles son las invenciones españolas que contiene, las localiza en cancioneros célebres y analiza algunas peculiaridades.

Palabras clave. Invenciones; emblemática; divisas; emblemas; cultura visual siglo XVl; cultura caballeresca.

Abstract. One of the most ingenious and subtle creations of late medieval and Renaissance court culture were devices or imprese, hybrid artifacts that, through 
word and image, used to send a message from their owner to whoever looked at them. There are hardly any testimonies with the image in the form of occasional devices (often ephimeral) known in Spain as "invenciones", which was held at festive events (tournaments, reed games, etc.). For this reason, the discovery in a French library of a manuscript that reproduces twenty Spanish "invenciones" (included in Cancionero general and other sources) with the motto and a drawing, is considered exceptional. This paper informs about the creator of the manuscript and details which are the Spanish "invenciones" it contains; locates them in famous Cancioneros and analyzes some peculiarities.

Keywords. Historic devices; Tournament imprese; Emblems; Badges; Visual culture 16th century; Chivalric culture.

\section{LAS INVENCIONES, DIVISAS OCASIONALES}

Entre las creaciones más ingeniosas y sutiles de la cultura cortesana bajomedieval y renacentista están las divisas o empresas, artefactos híbridos que mediante la palabra y la imagen enviaban un mensaje de su portador a quienquiera que las mirara. Desde la segunda mitad del siglo XIV y hasta finales del siglo XVII', los miembros de las familias reales, nobles, importantes eclesiásticos y cortesanos (incluidas las damas)2 ${ }^{2}$ así como más tarde destacados hombres de negocios de la burguesía, se esforzaron en idear (solos o con ayuda de un poeta o entendido en letras) una composición que mediante una sentencia breve y a menudo en latín (mote -alma-) y una imagen (pictura -cuerpo-) representara sus aspiraciones heroicas más nobles, cierto rasgo de su carácter, o algún mensaje de enamorado ${ }^{3}$.

Una variedad de las divisas o empresas eran las que se creaban ad hoc para ser ostentadas en algún acontecimiento festivo público, como torneos, juegos de cañas o de sortija, etc. destinadas a distinguir a su portador y a atraer la atención y comentario de los asistentes al festejo. Esta modalidad emblemática, de carácter ocasional, por lo general es mencionada en las fuentes españolas con el nombre de invención y se distingue de las divisas a las que a menudo se les añade el epíteto de "heroicas" en que:

1. suelen expresar el mote en verso y en español (pues se dirigen a un público amplio, desconocedor del latín u otras lenguas habituales en que los preceptistas recomendaban formular los motes de las divisas);

\footnotetext{
* Este trabajo se ha realizado en el marco del proyecto Biblioteca Digital Siglo de Oro 6 (BIDISO 6), con referencia: PID2019-105673GB-100, financiado por el Ministerio de Ciencia e Innovación de España por el programa estatal de Generación del Conocimiento (2020-2022), y se integra en el Grupo de Investigación Hispania (G000208) de la Universidade da Coruña.

1. Hay divisas anteriores y posteriores a esas fechas, pero es el rango de tiempo más frecuente de su uso. 2. Ver López Poza y Pena Sueiro, 2018.

3. Los conceptos más frecuentes expresados en las divisas o empresas solían ser ideales heroicos y amorosos, pero también pueden dar cuenta de contenidos de otra índole.
} 
2. emplean la agudeza con mayor frecuencia -incluso con variedades como la charada, el enigma, etc.-;

3. suelen tener un carácter efímero.

Pasado el festejo, solo dejaban rastro de haber existido si algún poeta o cronista se había ocupado de registrar una descripción (por lo general, el nombre -o con más frecuencia el título nobiliario- del propietario, el mote y una breve indicación de los objetos representados en la pictura). Raras veces se añadía lo que significaba el conjunto, y son muy escasas las imágenes que representen invenciones de este tipo, de modo que para el estudio de estas creaciones es preciso acudir a Cancioneros, Crónicas o Relaciones de sucesos que, aunque no nos aporten las imágenes, nos ayudan con sus rúbricas explicativas a completar las dos partes de que una divisa estaba formada (palabra e imagen) sin las cuales no puede llegarse a una interpretación cabal ${ }^{4}$.

\section{UN CANCIONERO MANUSCRITO QUE PERTENECIÓ A CHARLES DE CROŸ}

Gracias a una conversación con una colega francesa ${ }^{5}$, he topado con un interesante manuscrito que perteneció al duque Charles III de Croÿ Erschot (1560$1612)^{6}$, noble perteneciente a una de las grandes familias valonas que desempeñaron un papel relevante en la política de Flandes en los siglos XVI-XVII, primero bajo los duques de Borgoña y más tarde de los reyes españoles de la Casa de Austria.

\section{EL AUTOR}

Hijo de Philippe de Croÿ, tercer duque d'Ærschot (1526-1595), que fue gobernador general de Flandes en el reinado de Felipe II, Charles de Croÿ (fig. 1) se formó con Valerius (filólogo distinguido, amigo del famoso humanista belga Justo Lipsio) en el Colegio Trilingüe de la Universidad de Lovaina (de carácter erasmista). Cuando tenía 20 años, se casó con Marie de Brimeu, princesa de Chimay (1550-1605), viuda rica de familia de Picardía, que era una calvinista convencida, diez años mayor que él. Su influencia fue tan grande sobre el joven, que él abandonó la religión católica y la lealtad al rey de España.

En 1583, Charles era comandante de los ejércitos protestantes de Flandes. No pudo impedir el avance de Alejandro Farnesio y decidió reconciliarse con España en marzo de 1584. Se separó de Marie y volvió a abrazar la fe católica. Ese año entregó Brujas a los españoles, y al año siguiente, Gante. Durante los años siguientes, luchó junto a Alejandro Farnesio, logrando varias victorias. En 1590 se unió a las tropas

4. El grupo SIELAE, de la Universidade da Coruña, ha creado una base de datos -Symbola- que registra divisas o empresas históricas <https://www.bidiso.es/Symbola/>. Ver López Poza, 2017.

5. Debo la noticia de la existencia de este manuscrito a la profesora francesa Séverine Delahaye-Grelois, de la Université Paris-Est Créteil, a quien se lo agradezco.

6. I duque de Croÿ, IV duque de Aarschot, $\vee$ príncipe de Chimay y $\vee$ conde de Beaumont. Para detalles biográficos, ver Frédéric de Reiffenberg, 1815 y 1850. 
españolas que apoyaban a la Liga Católica en las Guerras de Religión francesas. En 1595 se convirtió en el cabeza de la familia de Crö̈, por la muerte de su padre, y en 1598 el rey francés Enrique IV convierte en ducado sus territorios de Croÿ. Al año siguiente recibe el honor de ser nombrado Caballero de la Orden del Toison de Oro por el rey español Felipe III, por acuerdo de su padre, Felipe II, que había fallecido en 1598 .

En diciembre de 1605, cuando tenía 45 años, ocho meses después de la muerte de su primera esposa, se casó con su prima, Dorothée de Croÿ (1575-1662), hija de Charles Philippe de Cröy, marqués de Havré. Las fiestas nupciales fueron fastuosas, con presencia de representantes de todas las casas reales de Europa. El duque era un reconocido protector de las letras y las artes, y su nueva esposa practicaba la poesía y se relacionaba con eruditos. Mantuvo correspondencia con el humanista y filólogo Erycius Puteanus, que había ocupado la cátedra de Justo Lipsio en Lovaina ${ }^{8}$. Tras la muerte de Charles, Dorothée le sobrevivió cincuenta años.

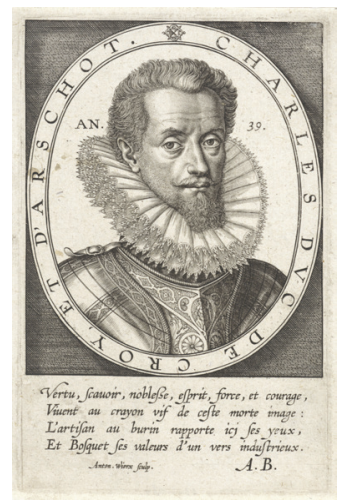

Fig. 1. Retrato de Charles de Croÿ, por Antonie Wierix, 1599 Rijksmuseum, Ámsterdam (Países Bajos)

Después de su segundo matrimonio, el duque convirtió el castillo de Beaumont en el centro de una esplendorosa corte. Gastó una gran parte de su fortuna en la compra de pinturas, manuscritos y monedas antiguas. Al mismo tiempo, le dedicó una gran atención a la gestión de sus dominios, especialmente sus residencias favoritas (castillos de Beaumont - Hainaut-y d'Heverlee). Encomendó al pintor Adrien de Montigny, entre 1596 y 1598, la realización de los famosos Albums de Crö̈, colección de cartularios sobre sus dominios, ricamente ilustrada (con pinturas al guache). Aunque eran documentos administrativos, estos cartularios ofrecían unas 2.500 vistas y mapas detallados de las villas y pueblos que pertenecían al duque, en áreas que abarcan el norte de la actual Francia y sur de Bélgica. Estos álbumes se consideran verdaderas joyas por su belleza y porque dan una fiel imagen de los Países Bajos meridionales a finales del siglo XVI y principios del siglo XVII.

7. Reiffenberg, 1850, pp. 172-173.

8. Dorothée era madrina de una hija de Erycius Puteanus. Sobre su correspondencia, ver Reiffenberg, 1850, pp. 176-177. 


\section{CONTENIDO DEL MANUSCRITO}

El manuscrito, realizado a lo largo de la segunda mitad del siglo XVI y datado hacia 1600, lleva por título: Chansons de Charles, duc de Croy et d'Arschot. En trois parties. Se conserva en la Bibliothèque Municipale de Valenciennes (Francia), con signatura Ms 0429. Dimensiones de $160 \times 203 \mathrm{~mm}$. en formato apaisado, en 350 hojas de papel. Su ficha lleva como autor a Charles III de Croÿ (1560-1612) y está compuesto por tres partes: la primera contiene poemas amorosos; la segunda (desde folio 162r) con la tabla alfabética de las canciones, se titula: Livre de chansons, escry de la main du prince de Chymay et appertenant à yceluy. La tercera parte (folio 340r) se titula: Libvre [sic] de tabelature contenant tous les hymnes et pseaumes des heures de Nostre-Dame, composés et mis en tabelature par moy Charles, syre et duc de Croy et d'Arschot.

Las dos primeras páginas contienen una carta manuscrita del duque, fechada en 1601, mediante la cual dona y dedica este cancionero personal a su prima Dorothée (con la que aún no se había casado) y explica que los últimos treinta años los ha dedicado a asuntos de guerra, de estado, de política, etc. y a la lectura de buenos autores tanto sobre asuntos divinos como humanos, pero que cuando era joven se entregó algún tiempo a recrearse con la poesía y la música para pasar el rato, y que escribió de su mano este libro de canciones compuestas por varios autores. Entre ellas, declara que él ha introducido algunos poemas suyos, así como algunas divisas y transcripción en tablatura (realizada por él mismo) de algunas de las canciones. Como, según expone, estas obras de juventud ya no le resultan de utilidad ni son propias de su edad, se lo entrega a Dorothée (que tenía quince años menos), para que le recuerde cuando haya muerto. Finaliza poniendo la fecha, enero de 1601; a continuación, el mote de su divisa: IE MAINTIENDRAY (que se repite en otros lugares, como los folios 9v y 162v), y su firma: Charles, Sire et duc de Croy et d'Arschot ${ }^{9}$.

Las cuarenta primeras hojas contienen dibujos de divisas, la mayor parte coloreados a la acuarela o guache, y algunos solo realizados como dibujos a tinta, que van insertos entre los poemas o canciones o en los márgenes. Las picturae van acompañadas del texto de los motes, unos en español (de los que aquí me ocupo), otros en francés y algunos en latín. Hacia el final, vuelven a aparecer algunos dibujos, pero son borradores, sin colorear y sin los motes de las divisas. A pesar de que algunos de los que reseñan el manuscrito dicen que los dibujos pudieron deberse a Dorothée, no hay evidencia que lo pruebe, y lo mismo pudo ser el autor el propio duque u otra persona.

El manuscrito es de enorme importancia para conocer los gustos de la época sobre lírica cortesana y requiere un estudio completo que atienda tanto a los textos como a la música que a veces aporta, pero nuestro interés principal se dirige ahora a las divisas que contiene. La mayor parte de las reproducidas en el álbum

9. La transcripción de la carta fue publicada por J. Margeart (1860, p. 667): «Lettre du duc Ch. de Croy a sa femme», en el Appendice et pièces justificatives. A Margeart se le ha olvidado transcribir la divisa del duque, que va delante de su firma. En el mismo catálogo, se da una descripción del manuscrito, cuyo registro es el 409 (p. 411). 
del duque de Cröy y d'Arschot, llevan motes en español, y parecen invenciones ocasionales realizadas a propósito para algún evento festivo. Quien realizó los dibujos pudo verlos en algún momento (bien in situ, como asistente al evento donde se ostentaron, o más probablemente como ilustraciones que acompañaran a alguna versión de la recopilación de Hernando del Castillo del Cancionero general (CG), pues todas aparecen allí registradas ${ }^{10}$. Otra posibilidad es que, teniendo delante el $C G$, el duque o quien realizara los dibujos pudo querer plasmar en imágenes los motivos descritos en las rúbricas del CG. Eso explicaría que, por ejemplo, en la invención representada en folio $16 r$ la vestimenta del caballero de luto se ajusta a la moda contemporánea del duque, y no a la que pudo vestir Luis de Torres en 1493, fecha en que al parecer la ostentó en Barcelona, como ahora explicaré.

He contrastado las veinte divisas con mote en español incluidas por Charles de croÿ en su cancionero manuscrito con las que aparecen reseñadas en dos cancioneros bien famosos por aportar descripciones de invenciones: el Cancionero General de Hernando del Castillo (1511) ${ }^{11}$ y el que conocemos como Cancionero Rennert, de principios del siglo $X \mathrm{VI}^{12}$. Aunque ninguno de ellos ofrece imágenes, sí que describen con palabras (las rúbricas) los motivos que aparecían en las picturae de las invenciones que describen, con lo que contribuyen a evocar las imágenes que fal$\tan ^{13}$. El manuscrito del duque resulta de gran utilidad para completar la información precisa que propicie una mejor comprensión del significado de estas invenciones.

Dado que el espacio del que dispongo en esta publicación es limitado, comentaré alguna de las invenciones insertas en el cancionero de Charles de Cröy y daré una lista de las veinte con mote en español que se incluyen en él, señalando el lugar que ocupan en el Cancionero General y (algunas) en el Cancionero de Rennert. Las divisas con motes en francés o latín serán objeto de otro estudio.

En el margen derecho del folio 16r (fig. 2) se inserta una pictura de un caballero vestido por completo de color negro, y con la moda de la corte de Felipe II. El mote que acompaña al dibujo reza:

A las cosas del placer

voy qual sé que he de volver

10. El Cancionero General, compilado por Hernando del Castillo, se imprimió en Valencia en 1511, y de él se hicieron muchas ediciones impresas. Se conservan también un número importante de manuscritos. Contiene poesía cancioneril, y dedica una sección a la recopilación de invenciones y letras lucidas por diversos caballeros en justas y torneos. A algunos se refiere el compilador por el nombre; otras, por el título nobiliario, y también hay diversos caballeros anónimos. Es asimismo de interés el que en ocasiones señale cómo se ostentó la invención y su modo de realización; por ejemplo: bordado en el brazo, bordado en la capa y el sayo, por cimera, etc.

11. Para citar sigo la edición de Joaquín González Cuenca (2004, vol. 2), que abrevio como CG.

12. Cito por la edición de Manuel Moreno, «Descripción codicológica LB1. MS. Additional 10.431, Biblioteca British Library de Londres». Ver en la bibliografía el registro Cancionero de Rennert, que abrevio como CR.

13. Ver Botta, 2005 y Kennedy, 2006. 


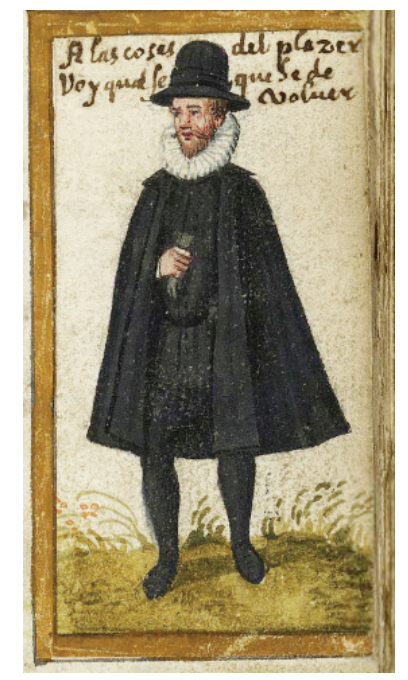

Fig. 2. Folio 16r

Esta invención la encontramos en el CG (2004, II, 509, p. 601), cuya rúbrica indica: «Del mismo, porque salió vestido de negro yendo a unas fiestas». Asimismo, en el CR (201, p. 90) la rúbrica indica: «El mismo salió a unas fiestas todo de negro porque sabía que no estava allí su amiga, dize:».

La rúbrica comienza por «el mismo» porque inmediatamente antes se ha citado otra invención del mismo propietario, Luis de Torres, hijo del Condestable de Castilla Miguel Lucas de Iranzo, que fue menino de los Reyes Católicos al servicio de su hijo, el príncipe don Juan (quien lo estimaba mucho). Gonzalo Fernández de Oviedo nos dice de él (Batallas y Quinquagenas II, pp. 385-388) que fue «tan gentil cortesano, que ninguno le acía ventaja en se saver vestir e invencionar; porque tuvo muy gentiles partes de cavallero, e demás de su gentil dispusición de su persona, era muy gentil latino e lindo poeta: trovaba e escribía muy bien...».

Esta invención la ostentó en una fiesta cortesana celebrada en la Lonja de Barcelona, en 1493, que describe brevemente Gonzalo Fernández de Oviedo. El festejo tuvo lugar unos pocos días antes de que Juan de Cañamares atentara contra el rey Fernando el Católico. La ciudad de Barcelona había organizado festejos «de mucho placer e regocijo», con danzas, juegos de cañas (algunas en navíos, con lo cual acabaron muchos caballeros en el mar). Asistieron los Reyes Católicos con sus hijos: Juan (de quien era menino este caballero) y las princesas Juana, María y Catalina (todos a excepción de la mayor, Isabel, que estaba de luto por la muerte de su esposo, el infante Alfonso de Portugal, muerto de una caída de caballo en 1491). Nuestro caballero estaba enamorado de una dama de la princesa Isabel, y como ella no podía acudir a la fiesta (pues su señora guardaba el luto), Luis de Torres expresó en su invención su falta de placer y su desinterés por el festejo, guardando él también su propio luto ante dicha circunstancia. Explica lo paradójico que es su atuendo negro para acudir a una fiesta. Luis de Torres ostentó la invención hacien- 
do bordar el mote en el terciopelo negro de la capa y en el sayo. También en la vaina de la espada.

Una invención muy famosa, que representa en la pictura una noria, con sus cangilones, aparece reproducida en el manuscrito del duque en el folio $22 r$ (fig. 3). El mote reza:

Los llenos, de males míos;

de esperança los vazíos

Esta divisa es otra de las que aparecen en el $C G(476$, p. 587) y en el $C R(208$, pp. 91-92). El primero incluye esta rúbrica: «El conde de Haro sacó una añoria, y dixo:»; la rúbrica del $C R$ : «El conde de Haro sacó unos alcaduçes con su añora, dize:»

El propietario manifiesta en primera persona que los cangilones que suben, los que van llenos de agua, equivalen a sus males de amor, que son muchos. Los que descienden, que van vacíos, metafóricamente equivalen a las nulas esperanzas que alberga con su amada. Sobre su propietario, el Conde de Haro, ha habido alguna discrepancia entre los investigadores, que dudan entre cuál pudo ser de dos hijos de Pedro Fernández de Velasco, I conde de Haro: Pedro o Bernardino Fernández de Velasco, aunque la mayoría se inclinan por atribuirla al último.

Una empresa semejante incluye Paolo Giovio en su Dialogo dell'imprese militari et amorose (1555) ${ }^{14}$. La pondera mucho e indica que perteneció a don Diego de Mendoza, hijo del Cardenal Mendoza, «valiente y esforzado caballero en las Guerras en que se halló con el gran Capitán Gonçalo Fernández de Córdoba» ${ }^{15}$. La traducción del diálogo de Alonso de Ulloa, refleja así la explicación de Giovio, que tomamos de la edición de Lyon, por Guillaume Rouillé de 1561, así como la xilografía con que se ilustra (fig. 4):

[...] habiendo tentado el vado con su dama y hallando estropiezos y malos pasos para poderla alcanzar, vencido del dolor, y aun desesperado, sacó una rueda de anoria con los alcaduces que sacan agua y la vacían; y porque de punto en punto cuasi la mitad de ellos está llena, recibiendo el agua, y la otra vacía, vaciándola, nascía de aquellos alcaduces un mote que decía: LOS LLENOS, DE DOLOR, Y LOS VACÍOS, DE ESPERANZA, que al juicio de todos fue tenida por empresa de sotil

14. Su redacción, según indica el autor, se remonta a 1551, aunque la princeps (Roma, Antonio Barre, 1555) se publicó tres años después de muerto Giovio y sin ilustraciones. Fue traducida al español por Alonso de Ulloa, como: Dialogo de las empresas militares y amorosas... y publicada en Venecia, por Gabriel Giolito de Ferraris, en 1558, pero al igual que la princeps, sin ilustraciones, que solo se incluyeron a partir de la edición de Guillaume Rouillé [Roviglio], en Lyon, 1559: «Dialogo dell'imprese militari et amorose... Con un Ragionamento di Messer Lodovico Domenichi nel medesimo soggetto». El mismo Rouillé publicó en Lyon en 1561 la traducción española ya con xilografías (ver en la bibliografía final)

15. Diego de Mendoza, segundo hijo del Gran Cardenal Pedro González de Mendoza y Mencía de Lemos (1468-1536). Luchó en la guerra de Granada y luego se distinguió a lo largo de todas las campañas de Italia, y la incursión en Cefalonia, a las órdenes del Gran Capitán. Los cronistas le llamaban «el Aquiles de los nuestros». Se destacó en la toma de Mélito (Nápoles) por lo que se le nombró conde de Mélito en 1506. 
invención y de única vista, porque el agua y la rueda daban presencia de subjecto a los que la miraban, y significaba que su dolor era sin esperanza de remedio.

Aunque la ilustración de la empresa de Giovio podía ayudarnos a hacernos una idea de cómo había sido ostentada una invención con el mismo motivo, sin duda gracias al álbum de Charles de Croÿ podemos tener la imagen tal como alguien la vio o la imaginó en el siglo XVI.

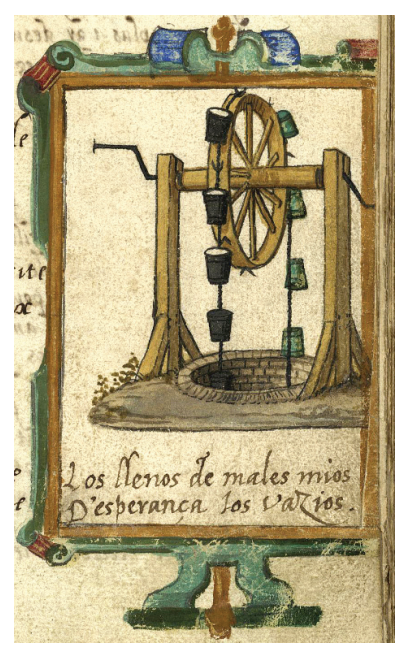

Fig. 3. Folio 22r

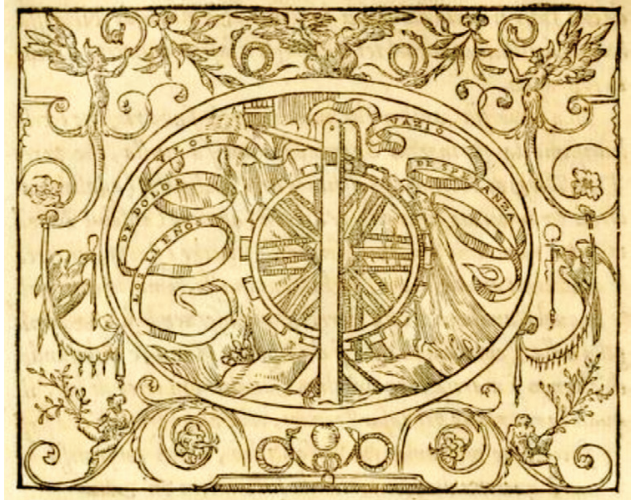

Fig. 4. Giovio, Dialogo de las empresas militares y amorosas... Lyon, Rouillé,

1561 , p. 26

Un ejemplo que puede inclinarnos por la hipótesis de que el duque (o quien realizara los dibujos) solo se inspirara en las rúbricas del CG y no en imágenes preexistentes, es el de la invención que aparece en el folio $19 \mathrm{v}$ del cancionero manuscrito (fig. 5). Se representa un manojo de cebollas, y el mote reza:

\section{Si acertare o si moriere \\ Contento ${ }^{16}$ con lo que fuere}

Si acudimos a buscar esta letra en el $C G(507$, p. 600) vemos que la propietaria de esta invención fue doña Leonor de Centelles, y que la rúbrica explica: «La marquesa de Cotrón traía bordados en el braço unos fuegos en forma como los de Cévola, y decía la letra: Si acertare o si moriere / Contenta con lo que fuere».

Por un error de comprensión, quien plasmó la pictura seguramente no vio el bordado de la marquesa, sino que se inspiró en la rúbrica para reproducirlo, y entendió «Cevola» como «cebolla», así que reprodujo la planta herbácea cebolla, cuando en realidad, por los «fuegos de Cévola» han de entenderse los fuegos de Mucio Scévola, el joven patricio romano que entró disfrazado en el campamento del rey Pórsena, que tenía sitiada a Roma, con la intención de matarlo. Se equivocó y mató a otro 
hombre, siendo arrestado y llevado a presencia del rey, ante el cual no solo no se amilanó, sino que, altaneramente, se autolesionó poniendo sobre el fuego de un brasero de sacrificios su propio brazo (con que había errado en su intento) y dijo en tono amenazante al monarca que otros muchos como él habían jurado acabar con su vida. Pórsena, impresionado, ordenó cesar el sitio y envió a Roma embajadores.

El mensaje de determinación que contiene el mote no tendría sentido vinculado a una mata de cebollas, mientras que sí lo tiene si se hubieran representado unas llamas sobre un ara, como se solía plasmar plásticamente la famosa escena de la anécdota.

Otra cosa interesante de esta invención es que la propietaria era mujer, y al parecer estimada por el acierto en el uso de invenciones, de lo cual dejó testimonio Juan del Enzina en un romance que contiene el mismo CG ${ }^{17}$.

Especialmente útil es contar con representaciones pictóricas en los casos en que el color es elemento significativo, o se alude a algún objeto poco conocido hoy. Por ejemplo, en la invención que aparece en el folio $17 \mathrm{r}$ del manuscrito, con el mote:

\section{Las bivas son las ofertas \\ Del amor de quien presumo, \\ Y el esperança las muertas \\ Y el galardón es el humo}

la pictura (fig. 6) resulta algo confusa, pero al acudir al CG y leer la rúbrica de esta invención, se aporta importante información: «Don Francés de Castelví [sic] sacó por cimera seis antorchas: las dos encendidas, que eran moradas, y las dos que eran verdes, muertas, y las otras dos, negras y humeando. Dixo:». Las antorchas moradas y encendidas representarían las penalidades y penitencia sufridas por el propietario con su amada; las verdes (color de la esperanza), al estar apagadas, dan a entender la falta de expectativas del amante -Castellví-, y las negras y humeantes su desolación y desconsuelo por la ausencia de recompensa a sus esfuerzos ${ }^{18}$.

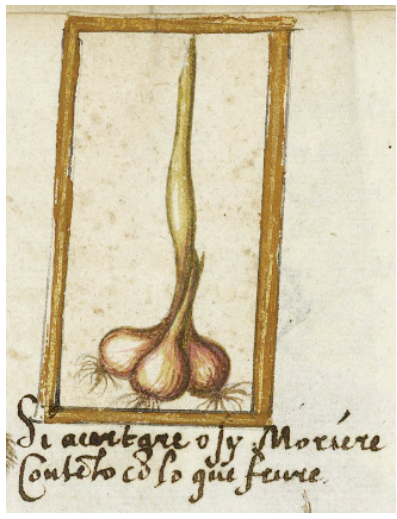

Fig. 5. Folio 19v

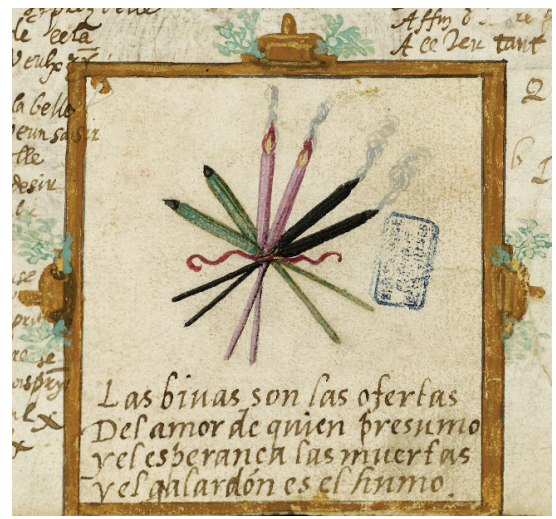

Fig. 6. Folio 17r

17. Ver Perea, 2007

18. Para los simbolismos de los colores, ver López-Fanjul, 2018. 
En el folio 20r del manuscrito de Charles de Cröy, aparece una imagen difícil de entender en nuestros días (fig. 7). Gracias a la rúbrica que precede al mote en el CG $(466 / 1$, p. 582) queda mucho más claro el sentido del conjunto: «Sacó don Diego López de Haro un previllejo con todas las colores sino la verde». El mote es:

$$
\begin{aligned}
& \text { Todas estas confirmaron. } \\
& \text { Sola esperança quedó } \\
& \text { Que non quiso por ser yo }
\end{aligned}
$$

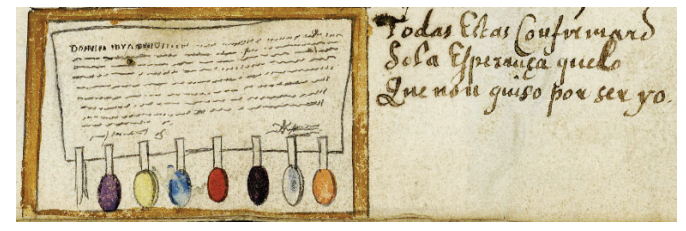

Fig. 7. Folio 20r

Como podemos ver, la pictura representa un privilegio (documento público con que se confirmaba un beneficio) con varios sellos colgando de distintos colores: morado, amarillo, azul, rojo, negro, blanco y naranja ${ }^{19}$. Falta un sello que, según la rúbrica del $C G$ era el verde (símbolo de la esperanza). Es una invención amorosa por la que su propietario nos da a entender que su dama se inclina por otro pretendiente o es inalcanzable por algún motivo.

El mismo concepto transmite otra invención del mismo propietario que aparece en el folio $21 \mathrm{v}$ (fig. 8), cuya pictura representa un laúd de color negro, con unas cuerdas verdes rotas y el mote:

Traigo, como veis, tristura Do placer nunca se alcança Después que quebró ventura las cuerdas del esperança

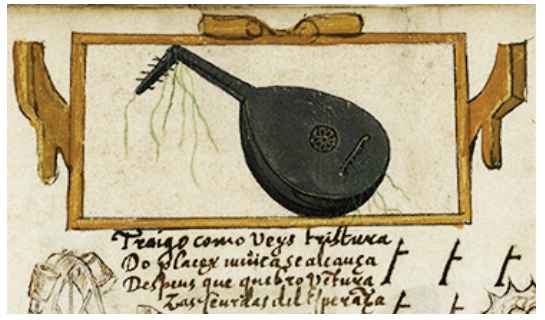

Fig. 8. Folio $21 v$

Estos ejemplos muestran que el hallazgo de este manuscrito supone una notable aportación (sobre todo por la escasez de testimonios plásticos de esta naturaleza) para una mejor comprensión de las divisas ocasionales históricas españolas que incluye, que posiblemente se exhibieron en acontecimientos festivos entre los años 1474 y $1489^{20}$ y que pudieron ser reinterpretadas en la segunda mitad del siglo XVI. Incluimos en dos ilustraciones (figuras 9 y 10) las imágenes restantes.

19. Cuesta Torre (2000, p. 69) indicaba al analizar esta invención de don Diego López de Haro: «desconozco cuáles son "todas las colores sino la verde", aunque en los privilegios rodados, que todavía se usaban en el siglo XV, el verde tenía un destacado papel». La imagen que nos proporciona este manuscrito ayuda a la comprensión.

20. González Cuenca, 2004, p. 576. 


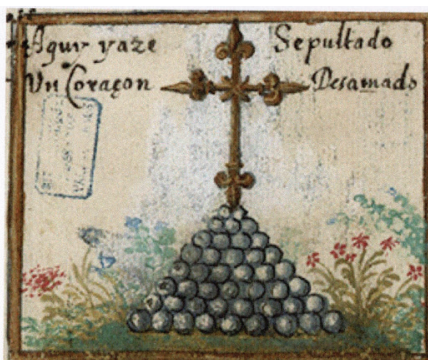

Fol. $8 r$

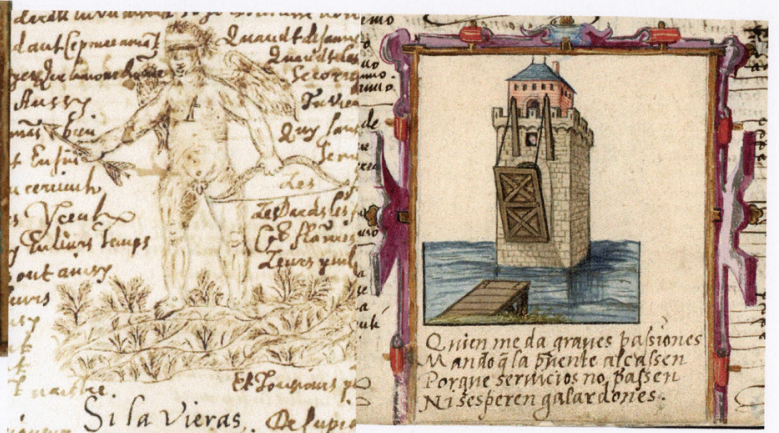

Fol. 9v Gulur St L veras. Ae paps. ar a mesmo fe hituras? Be

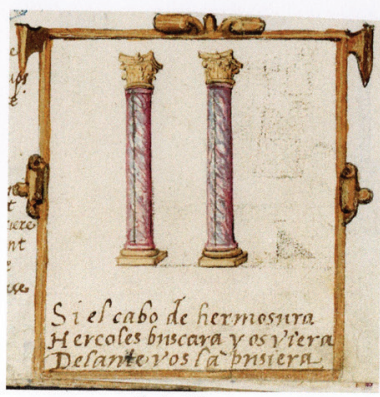

Fol. $13 r$

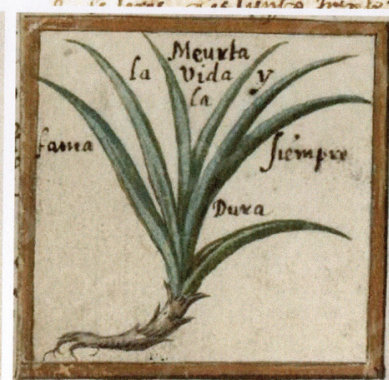

Fol. 13v
Fol. 12v

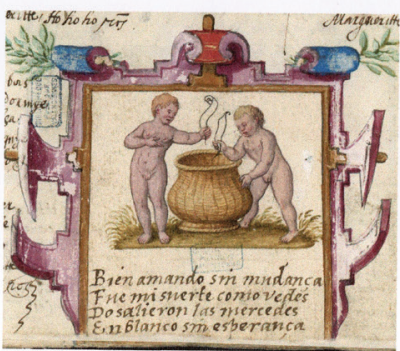

Fol. $14 r$

Fig. 9

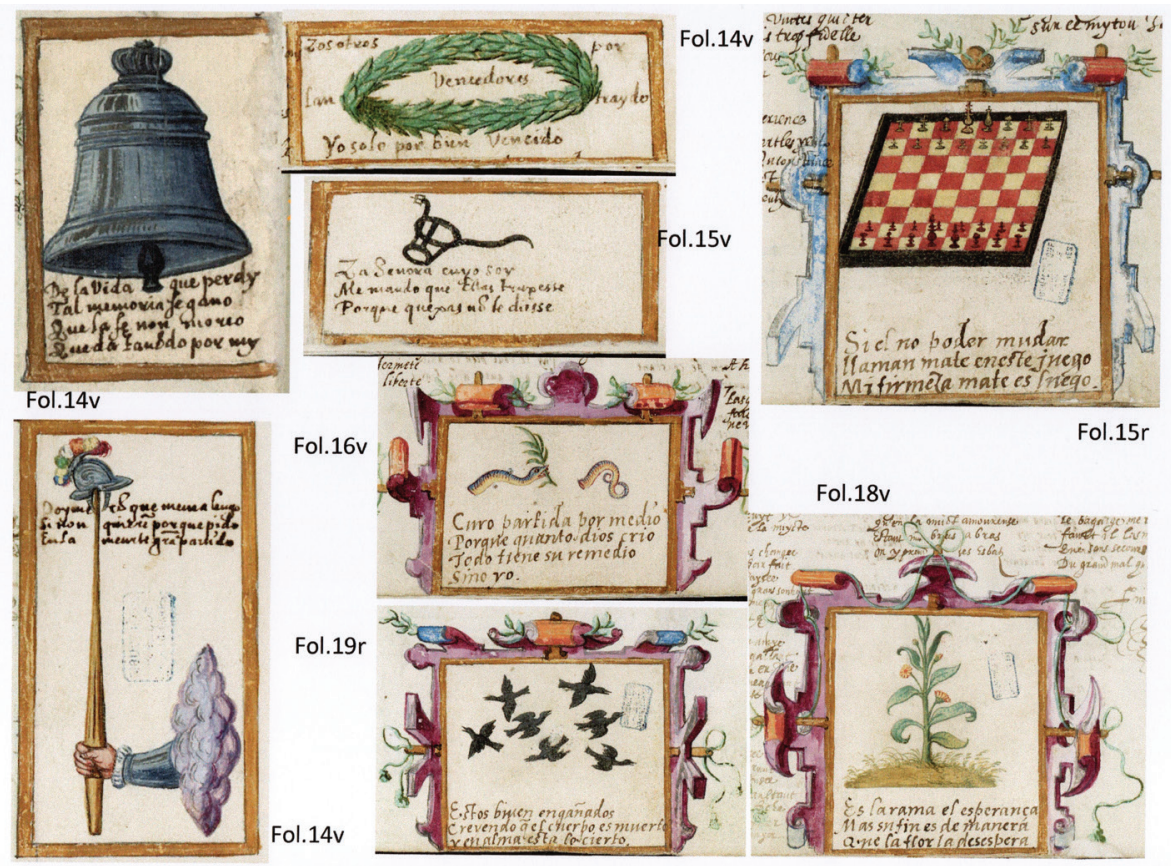

Fig. 10 
En el cuadro que sigue se relacionan las veinte invenciones españolas que contiene el cancionero manuscrito de Charles de Cröy, indicando el folio donde se encuentra cada una, el propietario al que lo atribuyen los editores del Cancionero general, la localización de la invención en sus principales ediciones y en el Cancionero Rennert cuando la invención figura en él. Todas estas divisas serán incluidas en la base de datos Symbola, con su particular análisis (<https://www.bidiso.es/Symbola>).

\section{LAS INVENCIONES ESPAÑOLAS EN EL MANUSCRITO}

Abreviaturas: $\mathrm{CG}=$ Cancionero General; $\mathrm{GC}=$ edición de Joaquín González Cuenca (en bibliografía final, bajo el registro «Castillo, Hernando del»); McP = MacPherson, Ian; CR = Cancionero de Rennert. Indicamos primero el número de orden de la invención en las fuentes citadas y luego la página.

\begin{tabular}{|c|c|c|c|c|c|}
\hline Folio & Pictura y mote & Propietario 21 & CG (GC) & $\begin{array}{c}\mathrm{CG} \\
(\mathrm{McP})\end{array}$ & $\mathrm{CR}$ \\
\hline \multirow[t]{2}{*}{$8 r$} & $\begin{array}{l}\text { Un montículo de piedras (perlas según } \\
\text { la rúbrica de CG) rematado por una } \\
\text { cruz dorada }\end{array}$ & \multirow{2}{*}{ Pedro Fajardo } & \multirow{2}{*}{$\begin{array}{l}526 \\
\text { p. } 608\end{array}$} & \multirow{2}{*}{$\begin{array}{l}74, \\
\text { p. } 82\end{array}$} & \\
\hline & $\begin{array}{l}\text { Aquí yaze sepultado } \\
\text { Un coraçon desamado }\end{array}$ & & & & \\
\hline \multirow{2}{*}{$9 v$} & $\begin{array}{l}\text { Imagen de un Cupido armado con los } \\
\text { ojos vendados }\end{array}$ & \multirow{2}{*}{ Gonzalo Chacón } & \multirow{2}{*}{$\begin{array}{l}560, \\
\text { p. } 622\end{array}$} & \multirow{2}{*}{$\begin{array}{l}\text { 108, } \\
\text { p. } 99\end{array}$} & \multirow{2}{*}{$\begin{array}{l}242, \\
\text { p. } 97\end{array}$} \\
\hline & $\begin{array}{l}\text { Si la vieras, } \\
\text { A ti mesmo te hirieras }\end{array}$ & & & & \\
\hline \multirow[b]{2}{*}{$12 v$} & $\begin{array}{l}\text { Una fortaleza rodeada de agua, con un } \\
\text { puente levadizo alzado }\end{array}$ & \multirow[b]{2}{*}{ Anónimo } & \multirow[b]{2}{*}{$\begin{array}{l}490 \\
\text { p. } 593\end{array}$} & \multirow[b]{2}{*}{$\begin{array}{l}38, \\
\text { p. } 65\end{array}$} & \\
\hline & $\begin{array}{l}\text { Quien me da graves passiones } \\
\text { Mandó que la puente alçassen } \\
\text { Porque servicios no passen } \\
\text { Ni se esperen galardones }\end{array}$ & & & & \\
\hline \multirow[b]{2}{*}{$13 r$} & Dos columnas & \multirow[b]{2}{*}{$\begin{array}{l}\text { Luis de } \\
\text { Montagudo }\end{array}$} & \multirow[b]{2}{*}{$\begin{array}{l}559, \\
\text { p. } 622\end{array}$} & \multirow[b]{2}{*}{$\begin{array}{l}\text { 107, } \\
\text { p. } 98\end{array}$} & \\
\hline & $\begin{array}{l}\text { Si el cabo de hermosura } \\
\text { Hércoles buscara y os viera } \\
\text { Delante vos la pusiera }\end{array}$ & & & & \\
\hline \multirow{2}{*}{$13 v$} & $\begin{array}{l}\text { Una planta verde, semejante al aloe } \\
\text { vera22 }\end{array}$ & \multirow{2}{*}{$\begin{array}{l}\text { Diego López } \\
\text { Pacheco }\end{array}$} & \multirow{2}{*}{$\begin{array}{l}502 \\
\text { p. } 598\end{array}$} & \multirow{2}{*}{$\begin{array}{l}\text { 50, } \\
\text { p. } 71\end{array}$} & \\
\hline & $\begin{array}{l}\text { Meurta [sic] la vida } 23 \\
\text { y la fama siempre dura }\end{array}$ & & & & \\
\hline
\end{tabular}

21. Los propietarios a veces están citados solo por su título nobiliario. Indico las identificaciones de González Cuenca y MacPherson.

22. La rúbrica del CG indica: «El marqués de Villena sacó una mata de yerba que dizen Siempreviva, y dixo:». 23. En CG: Muera la vida / y la fama siempre viva. 


\begin{tabular}{|c|c|c|c|c|c|}
\hline \multirow[b]{2}{*}{$14 r$} & $\begin{array}{l}\text { Dos niños sacando de un cesto } \\
\text { cédulas de sorteo }\end{array}$ & \multirow[b]{2}{*}{$\begin{array}{l}\text { Lorenzo Suárez } \\
\text { de Figueroa y } \\
\text { Mendoza }\end{array}$} & \multirow[b]{2}{*}{$\begin{array}{l}462 / 1 \\
\text { p. } 578\end{array}$} & \multirow[b]{2}{*}{$\begin{array}{l}\text { 5, } \\
\text { p. } 46\end{array}$} & \multirow[b]{2}{*}{$\begin{array}{l}183, \\
\text { p. } 86\end{array}$} \\
\hline & $\begin{array}{l}\text { Bien amando sin mudança } \\
\text { Fue mi suerte como vedes, } \\
\text { Do salieron las mercedes } \\
\text { En blanco, sin esperança }\end{array}$ & & & & \\
\hline \multirow[b]{2}{*}{$14 \mathrm{v}$} & Una campana & \multirow[b]{2}{*}{ Antonio Franco } & \multirow[b]{2}{*}{$\begin{array}{l}463 / 1 \\
\text { p. } 579\end{array}$} & \multirow[b]{2}{*}{$\begin{array}{l}\text { 7, } \\
\text { p. } 47\end{array}$} & \multirow[b]{2}{*}{$\begin{array}{l}184 \\
\text { p. } 86\end{array}$} \\
\hline & $\begin{array}{l}\text { De la vida que perdí } \\
\text { Tal memoria se ganó } \\
\text { Que la fe [que] non morió } \\
\text { Queda tañendo por mí }\end{array}$ & & & & \\
\hline \multirow[b]{2}{*}{$14 \mathrm{v}$} & Una corona de laurel & \multirow[b]{2}{*}{$\begin{array}{l}\text { Juan Téllez } \\
\text { Girón }\end{array}$} & \multirow[b]{2}{*}{$\begin{array}{l}506 \\
\text { p. } 600\end{array}$} & \multirow[b]{2}{*}{$\begin{array}{l}54, \\
\text { p. } 73\end{array}$} & \multirow[b]{2}{*}{$\begin{array}{l}197, \\
\text { pp. } 89- \\
90\end{array}$} \\
\hline & $\begin{array}{l}\text { Los otros por vencedores } \\
\text { l'an traído } \\
\text { Yo solo, por bien vencido }\end{array}$ & & & & \\
\hline \multirow[b]{2}{*}{$15 r$} & Un tablero de ajedrez & \multirow[b]{2}{*}{ Anónimo } & \multirow[b]{2}{*}{$\begin{array}{l}536 \\
\text { p. } 613\end{array}$} & \multirow[b]{2}{*}{$\begin{array}{l}84, \\
\text { p. } 87\end{array}$} & \multirow[b]{2}{*}{$\begin{array}{l}229 \\
\text { p. } 95\end{array}$} \\
\hline & $\begin{array}{l}\text { Si el no poder mudar } \\
\text { Llaman «mate» en este juego, } \\
\text { Mi firmeza mate es luego }\end{array}$ & & & & \\
\hline \multirow[b]{2}{*}{$15 v$} & $\begin{array}{l}\text { Un brazo que sostiene una lanza de } \\
\text { torneo con un capacete sobre ella }\end{array}$ & \multirow[b]{2}{*}{ Anónimo } & \multirow{2}{*}{$\begin{array}{l}546, \\
\text { p. } 617\end{array}$} & \multirow{2}{*}{$\begin{array}{l}94, \\
\text { p. } 92\end{array}$} & \multirow{2}{*}{$\begin{array}{l}233 \\
\text { p. } 96\end{array}$} \\
\hline & $\begin{array}{l}\text { Doyme }{ }^{25} \text { con que muera luego } \\
\mathrm{Si}^{26} \text { non quieren porque pido } \\
\text { En la muerte gran partido }\end{array}$ & & & & \\
\hline \multirow[b]{2}{*}{$15 v$} & Un bozal de perro & \multirow[b]{2}{*}{$\begin{array}{l}\text { Diego López } \\
\text { Pacheco }\end{array}$} & \multirow[b]{2}{*}{$\begin{array}{l}503 \\
\text { p. } 599\end{array}$} & \multirow[b]{2}{*}{$\begin{array}{l}51 \\
\text { p. } 72\end{array}$} & \\
\hline & $\begin{array}{l}\text { La señora cuyo soy } \\
\text { Me mandó que estas truxesse } \\
\text { Porque quexas no le diesse }\end{array}$ & & & & \\
\hline \multirow[b]{2}{*}{$16 r$} & Un caballero vestido de negro & \multirow[b]{2}{*}{ Luis de Torres } & \multirow{2}{*}{$\begin{array}{l}\text { 509, } \\
\text { p. } 601\end{array}$} & & \multirow{2}{*}{$\begin{array}{l}201 \\
\text { p. } 90\end{array}$} \\
\hline & $\begin{array}{l}\text { A las cosas del plazer } \\
\text { voy qual sé que he de volver }\end{array}$ & & & & \\
\hline \multirow[b]{2}{*}{$16 v$} & $\begin{array}{l}\text { Una serpiente dividida en dos trozos, } \\
\text { con una hierba en la boca } 27\end{array}$ & \multirow[b]{2}{*}{$\begin{array}{l}\text { Diego López de } \\
\text { Haro }\end{array}$} & \multirow[b]{2}{*}{$\begin{array}{l}485 \\
\text { p. } 591\end{array}$} & \multirow[b]{2}{*}{$\begin{array}{l}33, \\
\text { p. } 63\end{array}$} & \\
\hline & $\begin{array}{l}\text { Curó partida por medio } \\
\text { Porque quanto Dios crió } \\
\text { Todo tiene su remedio } \\
\text { Sino yo }\end{array}$ & & & & \\
\hline
\end{tabular}

24. La rúbrica del CG dice: «Otro sacó un capacete por cimera, puesto alto en una vara, a la manera que se muestra en las batallas o cercos de fortalezas en señal que piden partido, y dize:».

25. En el Cancionero Rennert, «Diome» en lugar de «Doyme».

26. A diferencia de los otros testimonios, en que figura: «y no quieren porque pido».

27. En la rúbrica del CG: «Del mismo a una sierpe partida por medio, que sacó por cimera, con una yerva en la boca, con que se cura poniéndola sobre la herida, y dixo:». 


\begin{tabular}{|c|c|c|c|c|c|}
\hline $17 r$ & $\begin{array}{l}\text { Seis antorchas anudadas: dos verdes } \\
\text { (apagadas), dos moradas (encendidas) } \\
\text { y dos negras (humeantes) } \\
\text { Las bivas son las ofertas } \\
\text { Del amor de quien presumo, } \\
\text { Y el esperança las muertas } \\
\text { Y el galardón es el humo }\end{array}$ & $\begin{array}{l}\text { Francesc de } \\
\text { Castellví }\end{array}$ & $\begin{array}{l}493, \\
\text { p. } 595\end{array}$ & $\begin{array}{l}41, \\
\text { p. } 67\end{array}$ & \\
\hline \multirow[b]{2}{*}{$18 \mathrm{v}$} & $\begin{array}{l}\text { Una planta de retama verde, con flores } \\
\text { amarillas. }\end{array}$ & \multirow{2}{*}{$\begin{array}{l}\text { Diego López de } \\
\text { Haro }\end{array}$} & \multirow{2}{*}{$\begin{array}{l}486, \\
\text { p. } 591\end{array}$} & \multirow{2}{*}{$\begin{array}{l}34, \\
\text { p. } 63\end{array}$} & \\
\hline & $\begin{array}{l}\text { Es la rama el esperança } \\
\text { Mas su fin es de manera } \\
\text { Que la flor la desespera }\end{array}$ & & & & \\
\hline \multirow[b]{2}{*}{$19 r$} & $\begin{array}{l}\text { Una bandada de pájaros negros } \\
\text { (cuervos) }\end{array}$ & \multirow{2}{*}{$\begin{array}{l}\text { Hernán Arias } \\
\text { Saavedra }\end{array}$} & \multirow{2}{*}{$\begin{array}{l}519, \\
\text { p. } 606\end{array}$} & \multirow{2}{*}{$\begin{array}{l}67 \\
\text { p. } 79\end{array}$} & \\
\hline & $\begin{array}{l}\text { Estos viven engañados } \\
\text { Creyendo que el cuervo es muerto } \\
\text { y en [el] alma está lo cierto }\end{array}$ & & & & \\
\hline \multirow[b]{2}{*}{$19 v$} & Un manojo de cebollas ${ }^{28}$ & \multirow{2}{*}{$\begin{array}{l}\text { Leonor de } \\
\text { Centelles }\end{array}$} & \multirow{2}{*}{$\begin{array}{l}507, \\
\text { p. } 600\end{array}$} & \multirow{2}{*}{$\begin{array}{l}55, \\
\text { p. } 73\end{array}$} & \\
\hline & $\begin{array}{l}\text { Si acertare o si moriere } \\
\text { Contento }{ }^{29} \text { con lo que fuere }\end{array}$ & & & & \\
\hline \multirow[t]{2}{*}{$20 r$} & $\begin{array}{l}\text { Un privilegio (documento antiguo) } \\
\text { con varios sellos colgando de colores } \\
\text { morado, amarillo, azul, rojo, negro, } \\
\text { blanco y naranja. Falta un sello, que } \\
\text { según la rúbrica del CG era el verde }{ }^{30} \text {. }\end{array}$ & \multirow[t]{2}{*}{$\begin{array}{l}\text { Diego López de } \\
\text { Haro }\end{array}$} & \multirow[t]{2}{*}{$\begin{array}{l}466 / 1 \\
\text { p. } 582\end{array}$} & \multirow[t]{2}{*}{$\begin{array}{l}13, \\
\text { p. } 50\end{array}$} & \multirow[t]{2}{*}{$\begin{array}{l}187, \\
\text { p. } 87\end{array}$} \\
\hline & $\begin{array}{l}\text { Todas estas confirmaron. } \\
\text { Sola esperança quedó } \\
\text { Que non quiso por ser yo }\end{array}$ & & & & \\
\hline \multirow[b]{2}{*}{$21 v$} & $\begin{array}{l}\text { Un laúd negro, con cuerdas verdes } \\
\text { rotas }\end{array}$ & \multirow[b]{2}{*}{$\begin{array}{l}\text { Diego López de } \\
\text { Haro }\end{array}$} & \multirow[b]{2}{*}{$\begin{array}{l}499, \\
\text { p. } 597\end{array}$} & \multirow[b]{2}{*}{$\begin{array}{l}47, \\
\text { p. } 70\end{array}$} & \multirow[b]{2}{*}{$\begin{array}{l}191 \\
\text { p. } 88^{31}\end{array}$} \\
\hline & $\begin{array}{l}\text { Traigo, como veis, tristura } \\
\text { Do placer nunca se alcança } \\
\text { Después que quebró ventura } \\
\text { las cuerdas del esperança }\end{array}$ & & & & \\
\hline \multirow{2}{*}{$22 r$} & Un pozo con su noria de cangilones & \multirow{2}{*}{$\begin{array}{l}\text { Pedro o } \\
\text { Bernardino } \\
\text { Fernández } \\
\text { Velasco }^{32}\end{array}$} & \multirow{2}{*}{$\begin{array}{l}476, \\
\text { p. } 587\end{array}$} & \multirow{2}{*}{$\begin{array}{l}24, \\
\text { p. } 57\end{array}$} & \multirow{2}{*}{$\begin{array}{l}\text { 208, } \\
\text { pp. } 91-92\end{array}$} \\
\hline & $\begin{array}{l}\text { Los llenos, de males míos } \\
\text { de esperança los vazíos }\end{array}$ & & & & \\
\hline
\end{tabular}

28. Como ya hemos explicado, quien realizó el dibujo que se copió en el manuscrito de Charles de Cröy cometió un error de interpretación de Cevola por Scévola o Escévola.

29. En Cancionero General, «contenta».

30. «Sacó don Diego López de Haro un previllejo con todas las colores sino la verde». Ha de entenderse que La Esperanza, (simbolizada por el color verde) se niega a confirmar la hidalguía del caballero.

31. Con variantes: Traigo, como veis, tristura, pues plazer nunca se alcança en la fe de mi esperança.

32. González Cuenca indica que «es problemático decantarse por uno de los dos hermanos Fernández de Velasco, hijos de don Pedro Fernández de Velasco» (2004, p. 587, nota 3). 


\section{BiBLIOgRAFÍA}

Botta, Patrizia, «La rubricación cancioneril de las letras de justadores», en «Dejar hablar a los textos». Homenaje a Francisco Márquez Villanueva, Sevilla, Universidad de Sevilla, 2005, vol. I, pp. 173-192.

Cancionero de Rennert, en la edición de Manuel Moreno, «Descripción codicológica LB1. MS. Additional 10.431, Biblioteca British Library de Londres», [2012], CIM. Cancioneros impresos y manuscritos, coord. Josep Lluís Martos, <http:// www.cancioneros.org/adjuntos/lb1.pdf>.

Castillo, Hernando del, Cancionero General, ed. Joaquín González Cuenca, Cancionero general, Madrid, Castalia, 2004, 5 vols.

Cuesta Torre, M. a Luzdivina, «Las invenciones de Diego López de Haro», en Proceedings of the Tenth Colloquium, ed. Alan Deyermond, London, Department of Hispanic Studies (Queen Mary and Westfield College), 2000, pp. 65-84.

Fernández de Oviedo, González, Batallas y quinquagenas, ed. Juan Pérez de Tudela y Bueso, Madrid, Real Academia de la Historia, 1983-2002, 4 vols.

Giovio, Paolo, Dialogo de las empresas militares, y amorosas / compuesto en lengua italiana por ... Paulo lovio...; todo nuevamente traduzido en romance castellano por Alonso de Ulloa; añadimos a esto las Empresas heroicas y morales del Señor Gabriel Symeon, En Leon de Francia, en casa de Guillielmo Rouille, 1561.

Kennedy, Kristin, «Do Cancionero Rubrics Help Solve Invenciones?», en Proceedings of the Thirteenth Colloquium, ed. Jane Whetnall y Alan Deyermon, Papers of the Medieval Hispanic Research Seminar, 51, 2006, pp. 137-146.

López Poza, Sagrario, «La base de datos "Symbola" de divisas o empresas históricas. Planteamiento y diseño conceptual», Studia Aurea, 11, 2017, pp. 93-109. DOI: <https://doi.org/10.5565/rev/studiaaurea.262>.

López Poza, Sagrario, y Pena Sueiro, Nieves, «Divisas o empresas históricas de damas. Algunos testimonios (siglos XV y XVI)», Imago. Revista de Emblemática y Cultura Visual, 10, 2018, pp. 75-97. DOl:<https://doi.org/10.7203/ imago.10.13155>.

López-Fanjul de Argüelles, Carlos, «Los colores en la heráldica de los libros de caballerías», Janus. Estudios sobre el Siglo de Oro, 7, 2018, pp. 19-54.

MacPherson, Ian, The «invenciones y letras» of the «Cancionero General», London, University of London, Papers of the Medieval Hispanic Research Seminar, London, Department of Hispanic Studies (Queen Mary and Westfield College), 1998.

Mangeart, Jacques, Catalogue descriptif et raisonné des manuscrits de la Bibliothèque de Valenciennes, Paris, Techener; Valenciennes, Lemaitre, 1860.

Perea, Óscar, «Una dama en el cancionero: la Marquesa de Crotone», en Estudio biográfico sobre los poetas del Cancionero General, Madrid, Consejo Superior de Investigaciones Científicas, 2007, pp. 97-108. 
Reiffenberg, Frédéric, Mémoires autographes du duc Charles de Croy, publiés, pour la première fois, par le baron de Reiffenberg, Bruxelles, Delevingne et Callewaert, 1815.

Reiffenberg, Frédéric, «Existence de grand seigneur au $\mathrm{xv}$ e siècle Charles de Croy», Archives Historiques et Littéraires du Nord de la France et du Midi de la Belgique, Troisième série, tome 1.er, Valenciennes, Au Boureau des Archives, 1850, pp. 157-186. 